\title{
ATUAÇÃO DO PSICÓLOGO NO CREAS EM MUNICÍPIOS DE PEQUENO PORTE
}

\author{
Rafael Bianchi Silva \\ Doutor em Educação - Unesp/Marília \\ Patrícia Cristiane Nogueira Cezar \\ Psicóloga - Faculdade de Jandaia do Sul (Fafijan)
}

\begin{abstract}
Resumo
O CREAS representa um importante dispositivo do SUAS, contribuindo para expansão do campo de atuação da Psicologia, o que tem fomentado discussões acerca da efetivação das práticas psicológicas nesse contexto. 0 presente artigo busca investigar as atribuições teórico-metodológicas utilizadas por psicólogos que atuam no CREAS em municípios de pequeno porte do estado do Paraná. Ao todo, foram entrevistados seis profissionais visando verificar se as práticas psicológicas estão sendo construídas de acordo com as orientações trazidas nas legislações, documentos inscritos e fornecidos pelo MDS, CFP e outros, buscando identificar os alcances e limites do profissional psi no referido contexto. Como resultado verificou-se que estes buscam adequar-se à realidade apresentada nas unidades de atuação conforme a territorização. Diversas ações realizadas por esses profissionais dialogam com os referenciais teóricos disponíveis, porém verifica-se a necessidade de materiais que contribuam para além do saber teórico, mas que possibilitem compreender a prática do psicólogo no CREAS. Palavras-chaves: centro de referência especializado de assistência social (CREAS); práticas psicológicas; atuação do psicólogo.
\end{abstract}

\section{THE PSYCHOLOGIST'S WORK IN THE SOCIAL ASSISTANCE SPECIALIZED REFERENCE CENTER IN SMALL MUNICIPALITIES}

\begin{abstract}
CREAS represents an important device of SUAS, contributing to the expansion of Psychology's field of action, which has promoted discussions regarding the execution of psychological practices in such context. The present article aims to investigate the theoretical and methodological attributions used by psychologists who work for CREAS in small towns in the State of Paraná. In total, six professionals have been interviewed in order to verify whether the psychological practices are being built according to the guidelines provided by legislations, documents registered and given by the MDS, CPF among others, in order to identify the psychologist professional's ranges and limitations in such context. As a result, it was verified that they seek to adapt to the reality presented in their working units according to territorization. Several actions performed by these professionals dialogue with theoretical references available, however it is noted the need for materials that contribute beyond theoretical knowledge, but that enable to understand the psychologist's practice at CREAS.

Keywords: social assistance specialized reference center (CREAS); psychological practices; psychologist's work.
\end{abstract}




\title{
LA ACTUACIÓN DEL PSICÓLOGO EN EL CENTRO DE REFERENCIA ESPECIALIZADO DE ASISTENCIA SOCIAL EN MUNICIPIOS DE PEQUEÑO PORTE
}

\begin{abstract}
Resumen
El Centro de Referencia Especializado de Asistencia Social (CREAS) representa un importante dispositivo del SUAS, contribuyendo para la expansión del campo de actuación de la psicología, lo que hay fomentado discusiones acerca de la efectuación de las prácticas psicológicas en ese contexto. El presente artículo busca averiguar las atribuciones teórico-metodológicas utilizadas por psicólogos que actúan en el CREAS en municipios de pequeño porte del Estado de Paraná. Al todo, fueron entrevistados seis profesionales visando verificar si las prácticas psicológicas están siendo construidas de acuerdo con las orientaciones traídas en las legislaciones, documentos inscriptos y previsto por el MDS, CFP y otros, buscando identificar los alcances y límites del profesional psi en el referido contexto. Como resultado se comprobó estos buscan adecuarse a la realidad presentada en las unidades de actuación conforme el territorio. Diversas acciones realizadas por esos profesionales dialogan con los referenciales teóricos disponibles, pero se verifica la necesidad de materiales que contribuyan para que además del conocimiento teórico puedan comprender la práctica del psicólogo en el CREAS.
\end{abstract}

Palabras clave: centro de referencia especializado de asistencia social (CREAS); prácticas psicológicas; actuación del psicólogo.

\section{INTRODUÇÃO}

De acordo com o Conselho Federal de Psicologia [CFP] (2011), existem diversas possibilidades de atuação dos profissionais psi nas Políticas Públicas de Assistência Social, pois através da intersetorialidade se criam espaços para intervenção junto ao trabalho de proteção social.

Para isso, torna-se plausível se pensar na práxis do psicólogo nas Políticas Públicas de Assistência Social, isto é, quais são suas atribuições e em quais referenciais o profissional juntamente com a equipe pautam-se e realizam as intervenções necessárias.

Nesse sentido, o presente artigo justifica-se pela necessidade de verificar como está sendo realizado o trabalho do psicólogo tendo como lócus de investigação no Centro de Referência Especializado de Assistência Social [CREAS], trazendo como objetivo verificar se as práticas psicológicas estão sendo construídas de acordo com as orientações trazidas nas legislações e diversos documentos inscritos e fornecidos pelo Ministério do Desenvolvimento Social [MDS], CFP e outros, fomentando discussões sobre os alcances e limites dos profissionais.

Segundo Macedo et al (2011), a Assistência Social representa um recente cenário para atuação dos profissionais da Psicologia e só foi possível devido ao 
seu reconhecimento como Política Pública que superou o modelo assistencialista e foi inclusa no capítulo de Seguridade Social da Constituição Federal de 1988, marcando os compromissos e responsabilidades dos entes públicos.

Por meio da Lei Orgânica de Assistência Social (LOAS) de 1993, regulamentou-se o Sistema Único de Assistência Social (SUAS), como uma política não contributiva, dever do Estado e direito de todo cidadão que dela necessitar, constituindo-se em um sistema de Política de Proteção Social junto a outras políticas quem visam promover cidadania. Para Macedo et al (2011), houve a reorganização da política de assistência social, visando promover maior efetividade de suas ações, aumentando sua cobertura.

Outra conquista importante se refere à aprovação da Política Nacional de Assistência Social (PNAS) em 2004, pautando-se na Constituição Federal de 1988 e LOAS. Esta por sua vez, reorganiza projetos, programas, serviços e benefícios de assistência social, definem as particularidades e especificidades territoriais, campo de ação, objetivos, usuários e formas de operacionalização da proteção social (Brasil, 2011).

A PNAS - Política Nacional de Assistência Social (2004), conforme citado anteriormente, deve prever a proteção básica e especializada, uma vez que se caracterizam por níveis de complexidade hierarquizados em média e alta complexidade.

Os serviços de proteção social básica devem ser organizados pela unidade estatal CRAS - Centro de Referência de Assistência Social que oferta o Serviço de Proteção e Atendimento Integral à Família - PAIF, visando a potencialização da família, o fortalecimento dos vínculos familiares e comunitários, a oferta de serviços que integrem a convivência, socialização e acolhimento das famílias nas quais não houve rompimento dos vínculos familiares, bem como promoção e inserção ao mercado de trabalho, prevenindo assim situações de vulnerabilidade e riscos pessoais e sociais (Brasil, 2004).

Conforme a Tipificação Nacional de Serviços Socioassistenciais (2009), os serviços de proteção especial de média complexidade referenciam a oferta de serviços que devem ser organizados pelas unidades públicas e estatais CREAS Centro de Referência Especializado de Assistência Social que obrigatoriamente oferta o Serviço de Proteção e Atendimento Especializado a Famílias e Indivíduos - PAEFI, visando atender a famílias e sujeitos que apresentam seus direitos violados, necessitando assim de maior estruturação técnico-operacional; bem 
como, o Centro de Referência Especializado para População em Situação de Rua (Centro POP) que obrigatoriamente oferta o Serviço Especializado para Pessoas em Situação de Rua.

Quanto à proteção especial de alta complexidade, o serviço ofertado é o acolhimento institucional que tem como objetivo promover a segurança a partir da acolhida a indivíduos e/ou famílias afastados temporariamente do núcleo familiar e/ou comunitários de origem, visando a proteção integral (Brasil, 2009).

A Tipificação Nacional de Serviços Socioassistenciais (2009) determina ainda que a proteção social especial de média complexidade inclui alguns serviços que devem ser ofertados de acordo com territorialização: (a) Serviço de Proteção e Atendimento Especializado a Famílias e Indivíduos (PAEFI); (b) Serviço Especializado em Abordagem Social; (c) Serviço de Proteção Social a Adolescentes em Cumprimento de Medida Socioeducativa de Liberdade Assistida (LA), e de Prestação de Serviços à Comunidade (PSC); (d) Serviço de Proteção Social Especial para Pessoas com Deficiência, Idosas e suas Famílias; (e) Serviço Especializado para Pessoas em Situação de Rua.

Partindo desse pressuposto, o presente artigo se deterá em abordar os Serviços de Proteção e Atendimento Especializado a Famílias e Indivíduos (PAEFI), uma vez que é uma obrigatoriedade em todas as unidades CREAS.

\section{A Inserção do Psicólogo nas Políticas Públicas}

Observa-se no histórico da regulamentação da Psicologia como profissão, íntimo vínculo com a chamada "Psicologia aplicada", na qual o lócus da atuação do psicólogo se limitava às áreas da educação, organizacional e do trabalho e clínica. Isso se evidenciava pelo fato dos cursos de Psicologia do país em sua maioria organizar as grades curriculares a partir desses três eixos (CFP; CREPOP, 2009).

Nesse sentido, o acesso aos serviços psicológicos se restringia àqueles com condições de custear o trabalho desses profissionais. Assim, construiu-se uma ideia de que o psicólogo só atuava com determinados grupos sociais, com práticas embasadas em aspectos psicoterápicos. Foi somente no final da década de 80 que se iniciaram gradativamente as articulações norteadoras da prática psicológica com o compromisso social, que fizeram os profissionais refletir se de fato estavam a serviço da realidade brasileira (CRESS; CFP, 2009). 
Essas reflexões acerca do compromisso ético dos profissionais psi com a realidade e sociedade brasileira favoreceram para construção de ideais voltados para a transformação social. Assim, de acordo com Macedo et al (2011), a última década foi marcada pela significativa inserção do psicólogo nas políticas públicas em todo território nacional.

Em contrapartida, Spink (2011) cita que é possível encontrar diversos estudos acerca do campo de atuação da Psicologia enquanto profissão, porém predomina-se ainda a área clínica, sendo o consultório o local de preferência para atuação dos profissionais.

Por esse motivo, a área de atuação do psicólogo junto às Políticas Públicas, em especial na Assistência Social, torna-se objeto de reflexão crítica devido à realidade brasileira apresentada. Assim, problematiza-se o campo clínico enquanto prática elitista, disponível apenas àqueles que a podem custear.

Partindo desse pressuposto, Spink (2011) menciona a necessidade de se levar os serviços de Psicologia também às áreas mais pobres, abrangendo assim os problemas sociais mais amplos, substituindo o individualismo pelo coletivo a partir de um trabalho voltado à relação do indivíduo com o contexto social vivenciado.

Destarte, verifica-se que a Psicologia vem construindo um terreno fértil junto ao trabalho social, buscando formar redes de apoio, de fortalecimento das redes comunitárias, bem como construir vínculos sociais, temática esta que, de acordo com Sarriera (2011), torna-se relevante diante do cenário individual.

Portanto, afirma-se a presença do psicólogo nas Políticas Públicas de Assistência Social, tendo em vista que o conhecimento trazido pelos profissionais psi reflete o compromisso acerca da defesa dos direitos sociais. Desta forma, a Psicologia nas Políticas Públicas contribui para além do melhor atendimento aos sujeitos, mas pode contribuir com a formulação e implementação dessas políticas, uma vez que o psicólogo compreende os aspectos subjetivos acerca dos fenômenos sociais visando assim a garantia dos direitos humanos (CFP; CREPOP, 2011).

De acordo com Silva (2003, p. 11 citado por CFP; CREPOP, 2009), através das Políticas Públicas o atual cenário brasileiro traz a possibilidade ao psicólogo de expressar suas práticas, bem como construir uma identidade de acordo com a necessidade brasileira, ao passo que favorece para expansão da Psicologia enquanto ciência. 
Desta forma, verifica-se a necessidade de fomentar discussões sobre os alcances e limites dos profissionais que tem como lócus de atuação o CREAS, pensando-se em como as práticas psicológicas estão sendo construídas de acordo com as orientações trazidas nas legislações e diversos documentos inscritos e fornecidos pelo Ministério do Desenvolvimento Social, Conselho Federal de Psicologia e outros.

\section{MÉTODO}

$\mathrm{Na}$ realização desse estudo de natureza qualitativa, foram realizadas entrevistas com seis profissionais de Psicologia que atuam no Centro de Referência Especializado de Assistência Social, nas quais as unidades ofertam o Serviço de Proteção e Atendimento Especializado a Famílias e Indivíduos (PAEFI). As participantes atuam em municípios de pequeno porte, do Estado do Paraná, sendo considerados, a partir dos critérios da PNAS $^{1}$ como pequeno porte I (no total de cinco deles) e pequeno porte II (o outro restante).

Os participantes são todos do sexo feminino, com faixa etária entre 20 e 45 anos.

Entre elas duas estão graduadas entre seis e sete anos e as outras quatro tem entre um e dois anos de formação. Quanto ao tempo de atuação no CREAS, uma participante atua há dois anos e meio; a segunda, há um mês; a terceira, há sete meses e as outras três estão entre um ano e um ano e meio de tempo no serviço. Além desse dado, destaca-se que três são concursadas e as demais possuem contrato por tempo determinado de serviço. Ao longo do artigo, as participantes serão identificadas por P1 a P6.

Para a análise dos dados, foram utilizados os documentos oficiais que abordam a atuação do profissional de Psicologia nas Políticas de Assistência Social.

É pertinente destacar que as entrevistas realizadas apresentam o modo como as psicólogas que atuam no CREAS compreendem suas atividades, representando uma forma de orientação e não um conjunto rígido de princípios metodológicos. Entretanto, buscou-se, a partir da fala das entrevistadas, uma aproximação à realidade analisada, de forma que a descrição de tais práticas possa contribuir com outros estudos, bem como para a formulação de novas

${ }^{1}$ Segundo a PNAS (BRASIL, 2004), os municípios de Pequenos I possuem até 20 mil habitantes, enquanto os considerados Pequenos II possuem de 20 a 50 mil habitantes. 
perspectivas de conhecimento e problematização da atuação do psicólogo no contexto indicado.

\section{RESULTADOS E DISCUSSÃO}

Promover a reflexão acerca do aprimoramento e mudanças do trabalho que deve ser desenvolvido pelos profissionais de Psicologia no CREAS favorece a compreensão da complexidade das situações atendidas, buscando discutir os referenciais teórico-metodológicos, bem como as estratégias de intervenção que poderão ser planejadas e efetivadas de acordo com as diferentes demandas.

O CREAS quando estabeleceu seu contexto de atuação, propôs o trabalho interdisciplinar, porém, para que o trabalho da equipe se faça eficaz, sugere-se que os profissionais tenham estabelecido seus respectivos papéis, funções e atribuições junto à equipe de forma esclarecida, bem como os serviços ofertados, rotina, procedimentos e instrumentos necessário para atuação na unidade CREAS (Brasil, 2011).

Partindo desse pressuposto, verificou-se junto às participantes da pesquisa se as mesmas conheciam os referenciais técnicos que orientam a atuação do(a) Psicólogo(a) no CREAS. O resultado a essa questão, obteve respostas positivas, como esclarecem os trechos abaixo:

Busquei informações pela internet, e a Pós-graduação me auxiliou bastante com a elaboração de atendimento aos assistidos do CREAS (P1).

Os referencias [...] foi através de cartilhas sobre a LOAS, SUAS, onde articula sobre o CREAS e seus modos de atendimento, artigos e leis sobre a atuação do psicólogo e capacitação [...]. Mas, sobre o papel especificamente do psicólogo foi encontrado pouco material (P2).

Através do acesso à internet, materiais do MDS, visita a outros profissionais da área e capacitações (P3).

[...] Através do encontro com um responsável da Regional, materiais que procuro na internet, sites sobre o CREAS no Brasil, além de visita em outras unidades CREAS (P4).

Através de curso de capacitação e documentos oficiais (P5).

Tive acesso às informações sobre o CREAS por meio da internet, pesquisei no site do CRP, CREPOP, MDS e também em alguns artigos que li. No entanto, as informações são amplas, relacionadas à proteção especial, não há muito material sobre a atuação do psicólogo. Também recebi informações em capacitações realizadas (P6).

Conforme os trechos acima, as mesmas verbalizaram que a busca por referências acontece principalmente via internet, através dos materiais e 
documentos disponibilizados pelo Ministério de Desenvolvimento Social (MDS) e Conselho Federal de Psicologia (CFP). Acrescentaram ainda, visita em outras unidades CREAS, além da troca de informações entre profissionais que atuam na mesma área.

O interesse e o acesso a essas informações possibilitam aos profissionais psi o esclarecimento e o planejamento da prática de atuação, permitindo o diálogo entre os demais profissionais da equipe. Segundo Afonso (2008) citado por Romagnoli (2012) deve haver a articulação do saber acadêmico juntamente com a necessidade de mudanças nas práticas profissionais, visando à adesão à proposta da Política de Assistência Social, bem como a produção de discursos e conhecimentos integrados à formação profissional.

Conforme indicado anteriormente, a formação em Psicologia prioriza as aplicações clínicas. Sendo assim, o diálogo com a Assistência Social acaba não acontecendo ou ainda sendo pouco abordado no cotidiano acadêmico, dificultando o ingresso do profissional nesse contexto. Este fato também foi indicado nos dados da pesquisa. A abertura ao mercado de trabalho nos serviços do SUAS, exigiu que os profissionais se ingressassem na área com pouco conhecimento acerca das peculiaridades desse campo de atuação, no qual o conhecimento veio surgindo gradativamente junto à atuação no CREAS, conforme pode ser visto nas descrições a seguir:

$\mathrm{Na}$ faculdade tive disciplinas sobre Psicologia Social, Comunitária, estudei sobre o SUS, mas não sobre o SUAS [...] Fui adquirindo conhecimento na prática profissional (P2).

A política de assistência social [...] surgiu como algo inusitado e novo. Quando comecei trabalhar nesta área, não tinha nenhuma noção sobre o que era e como funcionava, visto que na faculdade, apesar de ter tido a disciplinada de Psicologia Social, vi pouquíssimo sobre o SUAS e nada sobre o CREAS. Posso dizer que tudo o que sei hoje sobre o SUAS e minha atuação enquanto psicóloga do CREAS, adquiri pesquisando, perguntando, estudando e atuando (P4).

Quando fui convidada a atuar no CREAS, logo procurei informações sobre a unidade, pois durante a graduação, pouco foi discutido a respeito das Políticas Públicas de Assistência Social. Na grade havia disciplinas voltadas para as Políticas Públicas, porém era tudo muito amplo, muito reflexivo e crítico, nada tão específico que nos auxiliasse na prática (P6).

As entrevistadas apontam a preocupação quanto a questão da construção/apropriação de novos conhecimentos. Importante destacar que é através da busca por referencias técnicos que os(as) psicólogos(as) se apropriam do conhecimento, técnicas e instrumentos que possibilitem o atendimento ao 
público CREAS. O profissional psi, ao compreender e se apropriar acerca de sua atuação, é capaz de planejar e estruturar seu trabalho de acordo com as ações/atividades que poderão ser efetivados na prática cotidiana, prevenindo a mecanicidade ao manter o posicionamento crítico diante das situações apresentadas.

Tendo em vista a discussão acima, buscou-se identificar, por meio desta pesquisa, as principais ações/atividades cotidianas realizadas pelas psicólogas, descritos nos fragmentos abaixo:

As atividades são desenvolvidas através do acompanhamento dos sujeitos e seus familiares através do atendimento psicossocial ou psicológico quando necessário [...] São realizadas visitas domiciliares, atendimentos in loco (P1).

Atendimento de medida socioeducativa e acompanhamento com a família dos adolescentes; Acompanhamento com as famílias do grupo de crianças que frequentam o CREAS; Acompanhamento de outros casos de direitos violados encaminhados pelo conselho tutelar, saúde e CRAS (P2).

Atuação junto à assistente social; Visita domiciliar; Oficinas; Tomada de decisões; Reuniões, entre outros (P4).

Os atendimentos realizados são psicossociais, onde fazemos a acolhida e escuta qualificada dos usuários em situação de risco; Grupos de apoio para adolescente de medida socioeducativa; acompanhamento de crianças e adolescentes em audiências, delegacias e IML; Elaboração de estudo de caso juntamente com a equipe técnica e visitas domiciliares quando necessário; Elaboração de estudo psicossocial junto com a Assistente Social; Acompanhamento psicológico de curto prazo quando necessário e encaminhamentos para a rede (P5).

Procuramos sempre realizar atendimentos psicossociais, porém às vezes é necessário o atendimento psicológico, mas isso ocorre raramente. As atividades cotidianas são visitas domiciliares por vários motivos, acompanhamento de medidas sócio-educativas, realização de estudos sociais, relatórios ao fórum e/ou delegacias, escuta qualificada, acompanhamento de crianças e adolescentes com violação de direitos, orientações e encaminhamento para outras políticas públicas, realização de campanhas [...] (P6).

Em relação ao acompanhamento especializado, que parte do Plano de Acompanhamento - compreendendo-se atendimentos continuados que se fazem através das especificidades de cada caso -, são efetivados por meio de atendimentos individuais, familiares e em grupos, orientações, orientações jurídico-psicossocial, visitas domiciliares e outros, buscando novas possibilidades de interação do sujeito em seu contexto social (Brasil, 2011). Sobre as atividades/ações cotidianas, verificou-se ainda que algumas profissionais 
entrevistadas realizam atividades em grupos de acordo com a demanda territorial apresentada nos municípios, ou seja:

Trabalho com grupo de crianças e adolescentes negligenciados pelos pais ou responsáveis [...] (P2).

Trabalho em grupo com dependentes químicos $[\ldots]$, trabalho de prevenção junto aos sujeitos que frequentam o Peti - Programa de Erradicação do Trabalho Infantil (P3).

Mesmo com as especificidades apresentadas no cotidiano de cada profissional nas unidades CREAS devido a suas demandas, é possível visualizar que as informações citadas acima corroboram com as orientações trazidas nos documentos sobre a atuação dos profissionais no serviço de média complexidade, tais como:

[...] acolhida; escuta; [...] construção de plano individual e/ou familiar de atendimento; orientação sócio-familiar; atendimento psicossocial; $[\ldots]$ articulação da rede de serviços socioassistenciais; articulação com os serviços de outras políticas públicas setoriais; [...] mobilização para o exercício da cidadania; trabalho interdisciplinar; [...] estímulo ao convívio familiar, grupal e social; [...] dentre outros (BRASIL, s/d p. 5).

Verificou-se que o atendimento psicológico compõe a atenção psicossocial de forma priorizada. De acordo documento publicado em 2006 (citado em CFP; CREPOP, 2009 p. 51), esse serviço deve realizar o "acolhimento, escuta, atendimento especializado, em rede, interdisciplinar, encaminhamento e acompanhamento $[\ldots]$ ", que em linhas gerais, visa através de procedimentos técnicos promover ações psicossocioeducativas que garantam a proteção dos sujeitos, fortalecimento da autoestima, restabelecimentos do direito à convivência familiar e comunitária de forma digna de modo a enfrentar e superar a situação de violação de direitos.

No que se refere ao trabalho em grupo, observou-se que esse serviço ainda é difícil de ser realizado em municípios de pequeno porte, haja vista o menor fluxo de atendimento devido à baixa demanda. Sendo assim, conforme indicam os entrevistados, acaba-se por priorizar atendimentos individuais. De acordo com os documentos de parametrização, quando necessário, sugere-se o atendimento individual, preferencialmente nas entrevistas iniciais e anamnese, com a finalidade de preparar os usuários para sua inserção no grupo indicado (CFP; CREPOP, 2009).

A intervenção em grupo além de ser uma das técnicas possíveis do atendimento psicossocial, configura-se em um espaço de conscientização no 
processo inter e intrapessoal que busca o desenvolvimento do sujeito. A partir do grupo, objetiva-se "o espaço de convivência e o compartilhamento de experiências $[\ldots]$ o resgate da corporeidade e a reconstrução de relações e vínculos afetivos com a família, a comunidade e o grupo de pares" (CFP; CREPOP, 2009 p. 62).

Quanto ao trabalho de prevenção realizado com as crianças e adolescentes que frequentam o PETI (Programa de Erradicação do Trabalho Infantil), a atenção é fundamental para a garantia de direitos dos sujeitos identificados em situação de trabalho, bem como o acompanhamento a orientação necessária aos seus familiares (Brasil, 2011). Uma vez realizada a identificação do trabalho infantil, inclui-se a família no acompanhamento realizado pelo PAEFI e as atividades a ele relacionadas.

Foi também questionado aos profissionais como é articulado o atendimento às famílias e/ou indivíduos em situação de risco pessoal e social, com direitos ameaçados ou violados e em que momento há a participação do psicólogo. A essa questão, verificou-se que a postura adotada junto à equipe se apresenta da seguinte forma:

Todo processo é feito através de abordagem e sondagem para averiguar a veracidade dos fatos, em todos os momentos o psicólogo esta presente, sendo na visita preliminar em domicilio, seja no atendimento individual e coletivo no CREAS. Junto com a Assistente Social, viabilizamos relatórios semanais, onde é elaborado procedimentos diferenciados, ou seja, em casos emergenciais é feito relatórios para o Fórum, onde o Juiz determina a ação a ser empregada (P1).

Desde o momento que sou informada sobre a violação de direitos, começo a atuar juntamente com outros profissionais, seja através de visitas domiciliares, atendimento psicossocial ou atendimento individual, orientação, apoio e escuta psicológica. Minha participação ocorre em todo o momento, seja atuando diretamente ou auxiliando os demais profissionais (P2).

A participação do psicólogo ocorre desde o início [...] o primeiro atendimento é psicossocial através da visita domiciliar, após, marco o atendimento psicológico e quando necessário realizo os encaminhamentos (P3).

[...] é realizado de acordo com o caso, por exemplo, em um caso de suspeita de abuso sexual de crianças e adolescentes [...] procuramos realizar a escuta qualificada do sujeito de acordo com as circunstâncias da denuncia, em muitos casos realizamos um primeiro atendimento sem que a família saiba, para não coagir a criança, mas para isso temos o apoio do Conselho Tutelar que pode responder pela criança na ausência da família. Nos casos de medida sócio-educativa, são encaminhadas pelo Fórum, então realizamos visita domiciliar para comunicar a família e adolescente [...] (P6). 
Segundo a descrição abaixo, alguns profissionais ao receberem a denuncia ou encaminhamento, optam pelo estudo de caso, isto é:

O conselho tutelar ou o ministério público realizam o encaminhamento do sujeito, após, realiza-se estudo de caso, no qual os profissionais optam pela realização da visita domiciliar ou convidar a família para atendimento na unidade CREAS, após o atendimento psicossocial, realizam-se discussão do caso e os devidos encaminhamentos (P4).

Após a elaboração do PIA e análise de conjuntura dos fatos, realizase a observação de qual procedimento a ser realizado, com encaminhamentos para outros setores ou acompanhamento temporário. O psicólogo sempre está trabalhando em conjunto com o Assistente Social nessas situações (P5).

[...] Quando não é um caso de urgência que necessita de procedimentos imediatos, como violência sexual ou física, realizamos o estudo de caso (P6).

Segundo os documentos, essa estratégia permite o planejamento de ações de acordo com o caso, "além de criar condições de instrumentalização [...] a partir da realização do diagnóstico social e dos primeiros atendimentos, já é possível ter uma ideia das necessidades e dos encaminhamentos que podem ser feitos." (CFP; CREPOP, 2009 p. 55).

Portanto, confirma-se que a participação do psicólogo é unânime, realizada inicialmente através do atendimento psicossocial e se necessário atendimento psicológico, no qual é realizado o acolhimento e escuta qualificada do indivíduo.

Quanto aos encaminhamentos, este trabalho deve ser articulado com a rede para que o sujeito possa ter acesso a programas e benefícios de outras Políticas Públicas. No entanto, sabe-se que este procedimento não deve ser compreendido como uma transferência de responsabilidade, uma vez que os profissionais devem oferecer medidas de acompanhamento e controle (CFP; CREPOP, 2009).

Diante dos expostos acima, observou-se que o atendimento às famílias e/ou indivíduos em situação de risco pessoal e social, com direitos ameaçados ou violados dialoga e se complementa com as ações/atividades desenvolvidas nas práticas cotidianas citadas anteriormente.

Conforme documento publicado, o trabalho no CREAS necessita do compartilhamento de concepções pela equipe, de modo a contemplar as atribuições de cada profissional, uma vez que se tornam necessários os diversos saberes (Brasil, 2011). Esse ponto corrobora com as verbalizações dos profissionais entrevistados, pois, observa-se o constante diálogo entre a equipe interdisciplinar, principalmente na articulação de ações psicossociais 
mencionadas. No entanto, há que se considerar a especificidade da prática psi, isto é, diferenças do trabalho do psicólogo frente aos demais profissionais que atuam no CREAS. Quanto a essa questão, verificou-se que:

O trabalho do psicólogo se diferencia, pois ele não vai apenas buscar resolver a situação do indivíduo através de leis e etc, mas ele irá olhar para esse indivíduo [...] observando seu contexto familiar, sua história de vida, analisando como ocorrem seus comportamentos e sentimentos $[\ldots]$, proporcionando a este suporte necessário, o abordando de modo diferenciado dos outros profissionais, considerando que o indivíduo é único, devido a isto deve ser tratado com sua singularidade, possibilitando que esta pessoa tenha melhor qualidade de vida e consiga passar pelas situações vivenciadas da melhor forma possível (P2).

O psicólogo se preocupa em verificar as relações afetivas, os papeis dos indivíduos na dinâmica familiar, o afeto, vínculo e histórico familiar (P3).

O psicólogo pode participar de todas as ações do CREAS, articulando a sua atuação a um plano de trabalho elaborado em conjunto com a equipe interdisciplinar, porém se diferencia dos demais profissionais na forma como lança o olhar para pessoas, para famílias [...] suas necessidades, seus pontos fortes [...] fragilidade (P5).

O psicólogo é capaz de atuar juntamente com outros profissionais de forma eficaz, porém, é o profissional mais capacitado para realizar determinados procedimentos, por exemplo, uma escuta qualifica, é o psicólogo quem conduz o atendimento, ao abordar determinadas famílias é capaz de [...] compreender para além de sua situação sócio-econômica (P6).

Nota-se pelas falas acima a especificidade da atuação do psicólogo desde o momento do acolhimento, na qual a postura adotada aponta para compreensão do homem em sua integralidade. É o olhar do psicólogo sobre o sujeito que fortalece o momento da acolhida, podendo determinar a permanência ou não dos sujeitos e suas famílias na adesão do atendimento. Entende-se que estes necessitam de amparo devido a situação de fragilidade social ou pessoal, querem ser ouvidos e acreditados sem julgamentos, pontos que um atendimento mal planejado pode comprometer ou interromper (CFP; CREPOP, 2009).

Os trechos acima podem ser esclarecidos ainda na análise de Bock, Furtado e Teixeira (2001) ao pontuarem que a Psicologia enquanto ciência torna possível a compreensão do homem, "suas emoções, seus sentimentos, comportamentos [...] suas formas de aprender [...] inquietações, vivências, angustias e alegrias" (p. 152). Entende-se que o apoio de qualquer pessoa pode auxiliar diante das adversidades, mas, é o(a) psicólogo(a) o(a) profissional capacitado que 
"desenvolve uma intervenção no processo psicológico do homem [...] que tem a finalidade de torná-lo saudável [...] capaz de enfrentar dificuldades [...] (p. 153).

Embora o profissional de Psicologia disponha de especificidades singulares da profissão, que favorece para o enfrentamento e fortalecimento de vínculos das famílias em seus contextos, as psicólogas entrevistadas apontam que por motivos vários, os objetivos da atuação no CREAS são frustrados, conforme verificados nos fragmentos abaixo:

Percebo que os objetivos por vezes são frustrados, por não termos no município atividades de recreação para a faixa etária que necessitam de um foco, no âmbito biopsicossocial. Tais como atividades voltadas à cultura: Teatro, balé, aula canto, jogos de xadrez, aula de violão, sendo que as crianças e jovens não tem ocupação necessária e produtiva, que de suporte no processo de desenvolvimento e maturação (P1).

Não se pode realizar atendimento clínico, necessita-se então do trabalho em rede que nem sempre funciona, por esse motivo o trabalho do psicólogo no CREAS se torna ineficaz (P3).

Uma das maiores dificuldades que encontro e que torna o trabalho ineficaz ou frustrante é que visamos formas de possibilitar o protagonismo do sujeito [...] mas esse sujeito tem toda uma história de vida, toda uma trajetória [...], às vezes parece que ele está cristalizado e não colabora para mudança (P6).

Tendo em vista as dificuldades encontradas pelos profissionais, em questão os psicólogos que atuam no CREAS, o NOB-RH/SUAS (2006), prevê diretrizes para a política nacional de capacitação, a qual garante a coordenação e financiamento de capacitações ao profissional inserido nas Políticas Públicas de Assistência Social, com a finalidade de promover e propagar conhecimentos direcionados ao desenvolvimento das habilidades e capacidades necessárias para a atuação do profissional e garantia de direitos dos usuários.

No entanto, levantou-se junto às psicólogas entrevistadas, quais as maiores dificuldades encontradas na atuação do(a) psicólogo(a) no CREAS. Observou-se a necessidade de capacitações e/ou reuniões mensais que permitam o partilhamento de saberes e práticas, fato este que pode ser fundamentado com a descrição abaixo:

Considero várias dificuldades encontradas em nosso trabalho, entre elas: pouco referencial teórico que dê suporte a nossas ações enquanto psicólogas, poucas capacitações direcionadas aos psicólogos, observa-se que quando há capacitações, em geral as vagas contemplam em primeiro plano os coordenadores e assistentes sociais e em segundo plano os psicólogos (P6). 
Verificou-se ainda que a rede de atendimento não tem esclarecido as funções do(a) psicólogo(a) na Assistência Social. Por esse motivo, acaba-se por exigir que realize suas intervenções através do atendimento clínico, sem levar em conta o fato de que tal modalidade é característica dos serviços de saúde mental (como o CAPS, por exemplo). Esse trecho corrobora com o complemento a seguir:

Percebo dificuldades ao encaminhar o sujeito, por exemplo, uma criança, um adolescente que precise ser inserido em outros contextos [...] (P1).

Vejo como maior dificuldade, o não reconhecimento da função do psicólogo do CREAS, já que as pessoas em geral, bem como muitos profissionais esperam que seja realizado o atendimento clínico $[\ldots], 0$ que não é adequado. Muitos encaminhamentos principalmente do conselho tutelar, chegam solicitando este atendimento clínico [...] (P2).

Há dificuldades quando o psicólogo não está preparado para atuar, não sabe sobre seu papel e como funciona a política da Assistência Social (P5).

Considero ainda, dificuldade em estabelecer com a rede e demais profissionais, que a atuação do psicólogo no CREAS não pode ser voltada para o atendimento clínico [...] a rede não entende sobre proteção básica e especial, às vezes solicitam trabalhos de saúde mental $[. .$.$] vejo resistência nos encaminhamentos (P6).$

Essa é uma questão pertinente a ser colocada em discussão, pois se sabe que os atendimentos realizados no CREAS devem ter efeitos terapêuticos, mas, difere-se da psicoterapia devido ao planejamento de intervenções e objetivos (CFP; CREPOP, 2009). Partindo desse pressuposto, os(as) psicólogo(as) devem fomentar novas formas/propostas de intervenções.

Quanto à necessidade de referenciais técnicos, essa dificuldade destacou-se com unanimidade entre as profissionais entrevistadas, pois, compreende-se a necessidade de delimitar a função de cada profissional que atua no CREAS, seja entre a equipe, seja para a rede de atendimento ou usuários, bem como subsídios que amparem a atuação do psicólogo.

Falta de referencial teórico, que delimite as funções de cada profissional, pois em muitas situações o profissional atende demandas de outros profissionais (P3).

Vejo que ainda não há teorias que delimitem as funções de acordo com as demandas do psicólogo, assistente social e pedagogo, identificando as responsabilidades de cada profissional (P4).

Para finalizar essa discussão, aponta-se que os desafios estão lançados, haja vista que a realidade apresentada transforma-se à medida que também se 
constrói enquanto cenário de atuação. Esse fato requer metodologias e reflexões críticas em relação a atuação do profissional no serviço de proteção especial.

Por esse motivo, acreditamos que o presente artigo colabora ao processo de reflexão, buscando compreender a atuação dos profissionais de Psicologia no CREAS, contribuindo com considerações que fomentem discussões sobre as práticas psicológicas em um cenário propicio para a Psicologia enquanto ciência e profissão.

\section{CONSIDERAÇÕES FINAIS}

Em resposta ao objetivo destacado no início do presente artigo, que faz questionamento sobre como estão sendo efetivadas as práticas psicológicas no CREAS, buscou-se levantar junto aos profissionais como são utilizadas as referências técnicas relacionadas às orientações sobre os serviços do CREAS (disponibilizados pelo Ministério do Desenvolvimento Social e Combate a Fome, Conselho Federal de Psicologia e entre outros). Buscou-se identificar os pressupostos que embasam a atuação do profissional à medida que constroem uma identidade para além de psicólogo, mas também como profissionais da "Assistência Social".

A pesquisa realizada com as profissionais que atuam em CREAS, mesmo que localizados em municípios de pequeno porte, permite refletir acerca da prática de atuação e não somente pensá-la e/ou aceitá-la, mas também colocá-la em discussão sempre que necessário. No entanto, parece claro que esses profissionais procuram se adequar a realidade apresentada em cada unidade de atuação de acordo com a territorização, buscando o ajustamento das práticas cotidianas à medida que as constroem gradativamente.

Ao término da pesquisa, acredita-se que os principais objetivos propostos foram alcançados. Embora as dificuldades transcorridas na prática dos profissionais, tornou-se possível apreender questões relevantes ao trabalho no CREAS, assim como, se pensar na Psicologia que exige flexibilidade do profissional ao inseri-lo em contextos tão distintos entre si.

A partir do estudo acerca da atuação do profissional no CREAS, aponta-se a possibilidade do psicólogo constantemente vislumbrar cenários que trazem novas formas de atuação à medida que contempla novos e antigos desafios: antigos quando se pensa na inserção do psicólogo nas políticas públicas e, novos, ao se 
pensar em como o profissional busca se adaptar diante de sua realidade, de sua demanda.

Diante do exposto acima, há que se considerar o fato dos profissionais de Psicologia não terem uma participação efetiva na elaboração dos documentos legais que instituem a Política de Assistência Social, pode ter resultado na ausência de delineamentos do fazer psi nessa área, em especial no CREAS, proporcionando que outras categorias - como, por exemplo, o Serviço Social construíssem o saber da Psicologia nesse espaço, motivo que pode justificar a limitação de definições sobre a atuação do psicólogo, conforme indica Mello, (2011).

Destarte, observa-se que os profissionais das unidades CREAS, apresentam inquietações, haja vista as incertezas do trabalho na proteção social especial, isto é, quais atribuições são características da identidade do psicólogo, bem como quais as atribuições que deve adquirir junto à equipe.

Os resultados demonstram que a atuação do psicólogo no CREAS se difere de uma atuação tradicional, ao passo que coloca o profissional em contato com uma realidade que por vezes não foi base para diversos conhecimentos psicológicos apreendidos durante a formação inicial, necessitando a realização desse processo ao longo do percurso de trabalho nesse novo espaço.

Partindo desse pressuposto, há que se pensar na necessidade de rever as grades curriculares, incluindo a prática do psicólogo nas Políticas Públicas, em especial na Assistência Social, uma vez que vem abrindo portas de entradas a esses profissionais. Como forma de preencher essa lacuna ainda presente nos cursos de Psicologia (e na formação profissional como um todo), surgem os diversos documentos inscritos que trazem orientações importantes, mas nem sempre completas e esclarecidas.

Uma vez que a literatura sobre esse tema é escassa, considera-se que leis, portarias, resoluções e decretos acabam auxiliando na compreensão de como a Política de Assistência Social deve ser organizada para a garantia de direitos. Porém, uma vez que esses referenciais teóricos ainda são incompletos no que se refere à compreensão de ações do(a) psicólogo(a), dificulta-se o desenvolvimento de habilidades dos profissionais para que sejam capacitados a lidar com as especificidades do CREAS, o que consequentemente influencia ao efetivar as práticas psicológicas no referido contexto. 
Observa-se uma atenção do CREPOP (Centro de Referência em Psicologia e Políticas Públicas) que em parceria com o Conselho Federal de Psicologia, vem mapeando e contribuindo com pesquisas acerca da atuação do Psicólogo nas Políticas Públicas. Esse ponto é importante, em vista da superficialidade trazidas nos documentos que dificulta a compreensão do CREAS, bem como a identidade dos profissionais que nessas unidades atuam.

Diante dos fatos apresentados, verifica-se que não há uma resposta única ou sistemática que indique como estão sendo efetivadas as práticas psicológicas nessa área, mas que emerge por novos saberes que construam técnicas e instrumentos eficazes diante da realidade apresentada.

Portanto, deve-se refletir e fomentar sobre as condutas cotidianas de muitos profissionais que por vezes, tornam-se mecanicistas e impedem um novo olhar exigido pela realidade CREAS, o que implica em pensar se o Psicólogo está de fato contribuindo para uma Assistência Social voltada para efetivação dos direitos dos usuários.

\section{REFERÊNCIAS}

Bock, A. M. B., Furtado, O. \& Teixeira, M. de L. T. (2001). Psicologias: uma introdução ao estudo de Psicologia. 13 ed. Barra Funda - SP: Saraiva.

Brasil. Ministério do Desenvolvimento Social. (S/D). Orientações sobre a Gestão do Centro de Referência Especializado de Assistência Social - $1^{a}$ versão. Brasília.

Brasil. Ministério do Desenvolvimento Social. (2004). Política Nacional de Assistência Social. Brasília.

Brasil. Ministério do Desenvolvimento Social. (2006). Norma Operacional Básico de Recursos Humanos do SUAS - NOB-RH/SUAS. Brasília.

Brasil. Ministério do Desenvolvimento Social. (2009). Tipificação de Serviços Socioassistenciais. Brasília.

Brasil. Ministério do Desenvolvimento Social. (2011). Orientações Técnicas: Centro de Referência Especializado de Assistência Social. Brasília.

Conselho Regional de Serviço Social \& Conselho Federal de Psicologia. (2007). Parâmetros para atuação de assistentes sociais e psicólogos (as) na política de assistência social. Brasília. 
Centro de Referência Técnica de Psicologia e Políticas Públicas \& Conselho Federal de Psicologia. (2009). Serviço de proteção social a crianças e adolescentes vítimas de violência, abuso e exploração sexual e suas famílias: referências para atuação do psicólogo. Brasília.

Centro de Referência Técnica de Psicologia e Políticas Públicas \& Conselho Federal de Psicologia. (2011). Como os psicólogos e as psicólogas podem contribuir para avançar com o Sistema Único de Assistência Social (SUAS) informações para gestoras e gestores. Brasília.

Macedo, J. P., Sousa, A. P. de, Carvalho, D. M. de, Magalhães M. A., Sousa, F. M. F. de \& Dimenstein, M. (2011). O Psicólogo Brasileiro no SUAS: Quantos somos e onde estamos? Psicologia em Estudo, 16(3), p. 479-489.

Mello, E. P. (2011) E vamos à luta: O fazer do(a) psicólogo(a) no Centro de Referência Especializado de Assistência Social (CREAS). Dissertação de Mestrado, Programa de Pós Graduação em Psicologia, Universidade Federal do Ceará: Fortaleza. Recuperado em 20 de janeiro, 2013 da Biblioteca Digital Brasileira de Teses e Dissertações (BDTD): http://www.teses.ufc.br/tde_busca/arquivo.php?codArquivo=7827

Romagnoli, R. C. (2012). O SUAS e a formação em psicologia: territórios em análise. Ecos, 2(1), 120-132.

Sarrieira, J. C. (2010). Apresentação. In J. C., Sarriera, E. T., Saforcada (Orgs). Introdução à psicologia comunitária: Bases teóricas e metodológicas. Porto Alegre: Sulina.

Spink, M. J. (2011). Psicologia social e saúde: Práticas, saberes e sentidos. 8 ed. Petrópolis - RJ: Vozes.

Contato: tibx211@yahoo.com.br, patricia.ncezar@hotmail.com

Recebido em: 06/05/2013

Revisado em: 04/06/2013

Aceito em: 03/10/2013 